\title{
El acto cooperativo frente a las normas sobre protección al consumidor y frente a la legislación sobre la libre competencia*
}

\author{
Alonso Morales Acosta
}

\section{Introducción}

La presente ponencia trata sobre la vinculación que puede existir entre la regulación del derecho del consumidor y de la competencia con respecto al derecho cooperativo; en concreto, con el acto cooperativo.

En la primera parte hablaremos sobre el acto cooperativo y su vinculación con la relación de consumo, y en la segunda, sobre su relación con la libre competencia y la competencia desleal. Luego presentaremos nuestra posición sobre su aplicación en el ámbito cooperativo.

$\mathrm{El}$ acto cooperativo ha sido recogido de forma expresa en nuestro país mediante la Ley $29683^{1}$ (Ley que precisa los alcances de los artículos 3 y 66 del Decreto Legislativo 85, Ley General de Cooperativas).

* Ponencia presentada ante el Congreso Continental de Derecho Cooperativo, llevado a cabo en el marco de la XVIII Conferencia Regional ACI Américas en Guarujà-Sào Paulo-Brasil, del 6 al 10 de octubre de 2013. Ha sido complementada por la ponencia del doctor Dante Cracogna, basada en la misma materia, pero con un punto de vista diferente.

1 Artículo 1. Actos cooperativos.- Precisase que, de conformidad con lo dispuesto en el artículo 3 del Decreto Legislativo 85, Ley General de Cooperativas, cuyo Texto Único Ordenado fue aprobado por Decreto Supremo 074-90-TR, las cooperativas, por su naturaleza, efectúan actos cooperativos, los cuales se definen como los que se realizan internamente entre las cooperativas y sus socios en 
$\mathrm{Al}$ respecto, la Ley General de Cooperativas establece que el acto cooperativo cumple con las siguientes características:

1) Es un acto interno.- La persona jurídica opera como una gran organizadora u operadora logística cuyo fin es brindar un servicio a sus socios. Por ello, su operatividad se halla en el ámbito de las relaciones internas; es decir, no actúa con intereses económicos propios y diferentes del servicio de sus socios.

2) En cumplimiento de su objeto social.- Los actos jurídicos con los socios deben hallarse encausados dentro del objeto que la cooperativa ha previsto satisfacer a favor de ellos, pues en buena cuenta este refleja la necesidad del socio y la finalidad de la cooperativa.

3) No tiene fin lucrativo.- $\mathrm{Al}$ ser los socios los clientes de la cooperativa, lo lógico es que el precio asumido por estos para mantener el servicio no incluya una utilidad, sino únicamente el costo de su prestación, de su ampliación o del perfeccionamiento del servicio.

En este marco resulta pertinente analizar la relación de estos actos internos dentro de la esfera jurídica de las normas que protegen al consumidor, la libre competencia y la competencia desleal.

\section{El acto cooperativo y el derecho del consumidor}

\subsection{Finalidad del derecho de consumo}

El derecho de consumo ha establecido una tutela especial para el consumidor y sus relaciones en el mercado, pues la especialización ha dado una ventaja a quien desarrolla y oferta un bien o servicio: el conocimiento. Nadie tiene más información sobre el contenido y las características de su prestación que el proveedor, lo que evidencia la asimetría informativa respecto del cliente.

Debemos recordar que en una etapa inicial se buscó tutelar solo la problemática derivada de la asimetría informativa que existía entre la relación proveedor-consumidor final, para posteriormente extender dicha protección al microempresario, quien en algunos aspectos podía encontrarse desprotegido ante la falta de una adecuada información ${ }^{2}$.

cumplimiento de su objeto social. Los actos cooperativos son actos propios de su mandato con representación, estos no tienen fines de lucro.

$2 \mathrm{Al}$ respecto, véase el caso Chennyi E.I.R.L. vs. Kónica S.A., donde el Tribunal del Indecopi considera que "La Protección al Consumidor se basa en la Asimetría Informativa existente entre los proveedores y consumidores, donde aquellos se 
Así, con el objeto de contrarrestar dicha asimetría informativa o neutralizar sus efectos negativos, el derecho del consumidor establece normas y pautas que un proveedor debe seguir para garantizar que el consumidor reciba toda la información relevante sobre un bien o un servicio y con ello permitir que tome una decisión eficiente y acertada de consumo. De ello también se desprende la obligación del proveedor de entregar los bienes o prestar los servicios en las condiciones que han sido informadas o publicitadas a través de su oferta.

Ello es así porque, como señalan Natalia Fridman y Gloria Pérez Constanzó:

[...] los consumidores quieren que los mercados les ofrezcan la mayor cantidad de bienes y servicios, a los mejores precios y con apropiados estándares de calidad y seguridad; para ello, los consumidores necesitan tanto de información como de leyes apropiadas y políticas públicas que controlen y garanticen que las empresas cumplan con las normas y no incurran en prácticas desleales $(2005$, p. 2$)$.

En definitiva, el derecho del consumidor tutela que el consumidor cuente, en forma previa a la relación de consumo, con información relevante que le permita efectuar una adquisición eficiente de un bien o servicio.

\subsection{Relación de consumo}

El derogado Decreto Legislativo 716 (antigua Ley de Protección al Consumidor) nunca estableció una definición sobre la relación de consumo

encuentran en una posición ventajosa frente a la otra como resultado de su capacidad para adquirir y procesar información, consecuencia de su experiencia en el mercado y a su situación frente al proceso productivo [cursivas del autor]. En tal sentido, la Ley de Protección al Consumidor ampara más bien al que ocupa el último eslabón de la cadena de producción-consumo, es decir aquel que adquiere, disfruta o utiliza un bien o servicio, en principio, para la satisfacción de sus necesidades personales, familiares o de su entorno social inmediato".

Del mismo modo, en el caso Reynaldo Moquillaza S.R.L. vs. Milne \& CO S.A., el tribunal señala que "El pequeño empresario, al sufrir los efectos de la desigualdad en la relación de consumo, califica, en ciertos casos específicos, como consumidor para efectos de la aplicación de la Ley de Protección al Consumidor [cursivas del autor]. Dichos casos específicos serán aquellos en los que la adquisición o el uso, por necesidades de su actividad profesional, se refieran a productos en los que no pueda esperarse un grado de conocimiento o especialización que haga desaparecer la desigualdad entre el pequeño empresario y el proveedor del bien o servicio de que se trate" [cursivas del autor]. 
y sus alcances. Fue más bien la Resolución 001-2006-LIN-CPC/INDECOPI, de 30 de noviembre de 2006, la que aprobó los "Lineamientos sobre protección al consumidor" y dio a conocer los criterios reiterados en su jurisprudencia administrativa, los mismos que derivaron de aquel marco legal según la Comisión de Protección del Consumidor del Indecopi (Instituto Nacional de Defensa de la Competencia y de la Protección de la Propiedad Intelectual).

El citado decreto legislativo estableció que la relación de consumo se encuentra determinada por la concurrencia de tres componentes íntimamente ligados y cuyo análisis debe efectuarse de manera integral, ya que la ausencia de uno de ellos determinaría la ausencia de una relación de consumo. Dichos componentes son:

1. un consumidor o usuario;

2. un proveedor; $\mathrm{y}$

3. un producto o servicio materia de una transacción comercial

Posteriormente, el nuevo Código de Protección y Defensa del Consumidor (aprobado por Ley 29571, en adelante "Código del Consumidor"), en el numeral 5 del artículo IV de su título preliminar define a la relación de consumo como "la relación por la cual un consumidor adquiere un producto o contrata un servicio con un proveedor a cambio de una contraprestación económica". Obsérvese que se prescinde de la referencia a una "transacción comercial".

Como se puede apreciar, la nueva ley define con gran precisión el concepto de relación de consumo y cubre de esta manera el vacío que tenía la antigua normativa. Además, extiende la tutela a las etapas previa y posterior de la citada relación de consumo. En buena cuenta, lo que pretende el derecho del consumidor es que en una etapa previa a la elección se cumpla con un estándar de información, con el objeto de que la prestación ejecutada coincida con lo debidamente informado (idoneidad).

En la etapa previa se encuentran todas aquellas actividades que abarcan la etapa preliminar de una relación de consumo, la publicidad y las ofertas que realiza un proveedor para atraer a sus clientes; mientras que la etapa posterior estaría comprendida por todas las consecuencias que derivan de una relación de consumo y que incluso podrían tener una vinculación lejana o mediata con esta, por ejemplo: el reporte indebido a la central de riesgos de un consumidor que efectivamente cumplió con pagar oportunamente su crédito, o el caso de las empresas 
de servicios automotrices posventa que no tienen los repuestos o accesorios adecuados para arreglar un vehículo.

\subsection{Actos de las cooperativas}

Antes de introducirnos en este punto, debemos distinguir con claridad entre los actos que las cooperativas llevan a cabo en cumplimiento de su objeto social y los actos que se alejan de este.

En efecto, por un lado tenemos los "actos de comercio", que son los que la cooperativa realiza con terceros no socios, en los que generalmente se puede apreciar la existencia de un propósito de lucro, característica esencial de las sociedades mercantiles; y, por otro lado, los "actos cooperativos", que son todos aquellos actos internos (cooperativa-socios) realizados en cumplimiento del objeto social y que carecen de finalidad lucrativa.

Si bien los actos cooperativos no califican como una "transacción comercial", dentro de ellos sí se puede identificar una "contraprestación económica" particular (de cada socio) que comprende estrictamente el "costo económico" ( $\sin$ fin de lucro) de la prestación (servicio de crédito, de vivienda, educativo, etc.) brindada por la cooperativa.

Si bien dentro de la noción de "transacción comercial" no cabe de ninguna manera incluir al "acto cooperativo", el que el "Código del Consumidor" haya dejado de lado dicho concepto (el de "transacción comercial") para referirse únicamente al de "contraprestación económica" podría ser el fundamento para legitimar su aplicación a dichos actos, como se explicará más adelante.

\subsection{Posición de la agencia de competencia de protección al consu- midor en el Perú (Indecopi)}

En el Perú, la entidad que tutela los intereses del consumidor y sus relaciones dentro del mercado es el Indecopi.

Con relación a nuestro tema, el Indecopi excedió inicialmente su competencia extendiendo indebidamente el sentido de lo que es una "transacción comercial" para abarcar y resolver las materias relacionadas con los actos cooperativos; incluso llegó a pronunciarse no solo sobre las particularidades del servicio cooperativo (v.g., que se brinde información sobre el saldo del crédito o que no se efectúen cobros indebidos), sino también sobre el reintegro de aportaciones y excedentes, invadiendo así aspectos puramente societarios. 
Con el tiempo, su jurisprudencia evolucionó y dejo fuera del campo de la relación de consumo a los actos corporativos que se realizan dentro de la persona jurídica cooperativa, como los vinculados a sus órganos internos y la mencionada participación económica de los socios (aportaciones y excedentes), con lo que quedó clara su actual tendencia de declararse competente en materias solo relacionadas con las prestaciones particulares de la cooperativa a sus socios y no en los aspectos relacionados con el ámbito estrictamente societario.

En tal sentido, y bajo la vigencia del "Código del Consumidor", se sustituyó la noción de "transacción comercial" por la de "contraprestación económica" y se expidió la Resolución Final 1896-2011/SC2-INDECOPI, mediante la cual el Indecopi precisó:

Los fondos que permiten a una cooperativa de ahorro y crédito brindar el servicio de financiamiento a sus asociados, ordinariamente provienen del propio dinero entregado por dichos sujetos. Sin embargo, ello no enerva la existencia de una relación de consumo entre las partes dentro del referido contexto, pues, al margen del origen de dichos fondos, la cooperativa actuando como proveedora presta dinero a los asociados, siendo que estos se convierten en sus consumidores [cursivas del autor].

De igual modo, la regla aplica a las cooperativas de vivienda, que estructuran un proyecto inmobiliario, adquieren un terreno, realizan un proyecto de habilitación urbana y entregan lotes o casas construidas para sus socios, o también a las de servicios educacionales, que generan una infraestructura educativa en favor de los hijos de los socios, y en general a cualquier cooperativa de usuarios. En todos estos casos existe una contraprestación económica y con ello queda abierta la competencia del Indecopi para atender a los consumidores.

\subsection{Posición del ponente}

Consideramos que desde el punto de vista de la dogmática jurídica existen argumentos razonables para sostener que el acto cooperativo no genera una relación de consumo, toda vez que no deriva de una transacción comercial. En esa misma línea, incluso se sostiene que el concepto "contraprestación económica" (usado por el Código del Consumidor en lugar de "transacción comercial") resulta insuficiente para abarcar al "acto cooperativo", dado que se halla en el contexto de un contrato de cambio, que es una relación de mercado entre agentes con intereses opuestos: comerciantes-consumidores. 
En ese sentido, el jurista Dante Cracogna, reconocido internacionalmente por su solvencia en derecho cooperativo, explica:

[...] la incongruencia de pretender aplicar la legislación de defensa del consumidor a las cooperativas, ya que en ellas no tiene lugar el presupuesto básico que motiva dicha legislación: proteger al consumidor de los excesos en que puede incurrir el proveedor en la búsqueda de su mayor beneficio, lucro o ganancia. Al no tener lugar ese presupuesto deviene inaplicable dicha legislación. En efecto, ¿de quién se protegería al asociado que es a la vez dueño, gestor y usuario de los servicios de la cooperativa? ¿Acaso a sí mismo? [...]

$$
\text { [...] }
$$

La cooperativa no tiene el carácter de un proveedor de bienes o servicios enfrentado con el asociado para lucrar a sus expensas, como sucede en la actividad comercial corriente. En la cooperativa, los asociados se reúnen para adquirir en común bienes o procurarse servicios que van utilizando a medida que los necesitan; la cooperativa actúa como una despensa o almacén común de los asociados del cual se van abasteciendo conforme con sus particulares requerimientos. Lejos se encuentra esta situación, pues, de la de un proveedor común que compra para revender a los consumidores lucrando con la diferencia entre el costo y el precio de venta. Si en la cooperativa llegara a existir una diferencia entre el costo y el precio que los asociados abonan por los bienes, entonces se les reembolsará dicha diferencia por vía de retorno proporcional a las adquisiciones realizadas por cada uno (6-10 de octubre de 2013).

En efecto, por un lado tenemos a "un especulador mercantil" que busca maximizar sus intereses aprovechando la asimetría informativa del consumidor; y por otro lado a la "cooperativa", que no es más que la "representación colectiva" de los consumidores y que como tal exige ser tutelada por el "derecho del consumidor" y no ser vista simplemente como un proveedor de las prestaciones a sus socios.

El acto cooperativo desplaza el régimen protectorio del consumidor puesto que implica la eliminación de la antítesis proveedor-consumidor que viene a quedar sustituida por un régimen de mutualidad económica en el seno de la cooperativa donde la calidad de asociado deviene sustancial para interpretar la relación con la cooperativa: el asociado obtiene los servicios precisamente por ser miembro (dueño) 
de la cooperativa, con lo cual se confunden las calidades de proveedor y consumidor. A ello debe agregarse que, conforme con el régimen de la Ley 20.337 - y, en general, de las leyes latinoamericanas -, sola y exclusivamente los asociados pueden formar parte de los órganos sociales de la cooperativa: asamblea, consejo de administración y órgano de fiscalización (Cracogna, 6-10 de octubre de 2013).

Vale decir que en la medida en que se sostenga que la relación de consumo comprende solo el cambio en el mercado y no el autoservicio generado por los propios consumidores, se considerará que el acto cooperativo resulta excluido de los alcances de la legislación de protección al consumidor.

No obstante lo mencionado, y desde otro punto de vista, cabe advertir que las corrientes doctrinarias del derecho del consumidor han llegado a la siguiente conclusión:

La noción de acto de consumo, así como el resto de definiciones que se han dado sobre el consumidor hasta el momento son incompletas. Los criterios que llevan incorporados no son suficientes para resolver los problemas que se plantean en el acontecer diario (Botana \& Ruiz, 1999, p. 33) [cursivas del autor].

En efecto, se entiende

[...] que en términos generales, pueden distinguirse dos nociones diferentes de los consumidores: una noción concreta o estricta, centrada fundamentalmente en quienes adquieren bienes o servicios para uso privado, y una noción abstracta o amplia, que incluye a todos los ciudadanos en cuanto personas que aspiran a tener una adecuada calidad de vida (Botana \& Ruiz, 1999, p. 29) [cursivas del autor].

Lo que interesa es proteger "en especial medida a aquellos que se encuentran en una posición de mayor debilidad frente al empresario-entidad y que, en la gran mayoría de las ocasiones, coincidirán con las del consumidor" (Botana \& Ruiz, 1999, pp. 30-31) [cursivas del autor].

A ello se debe que,

[...] habiendo llegado hasta un concepto amplio de consumidor como sujeto del tráfico económico frente a la empresa organizada, empieza a perfilarse la idea del consumidor final de bienes y servicios para uso privado, tanto como adquiriente de bienes de consumo como usuario de servicios públicos y privados (Botana \& Ruiz, 1999, p. 31) [cursivas del autor]. 
Puede apreciarse que se busca tutelar la asimetría informativa proveniente de una empresa, sea que esta les pertenezca o no a los socios, puesto que de existir un estándar en el mercado para el otorgamiento de información relevante, no resulta razonable que una empresa cooperativa (que actúa en interés de sus socios los consumidores) tenga un estándar inferior al de una empresa mercantil (cuyo interés es justamente la especulación y la maximización de los beneficios de sus inversionistas de capital).

Paradójicamente, en el campo fáctico se ha apreciado que algunas cooperativas actúan por debajo del estándar adecuado de entrega de información relevante, afectando con ello los derechos de información e idoneidad de sus propios socios, con lo cual se alejan incluso de los principios y fines del cooperativismo.

¿Cómo explicar que se materializan prácticas anómalas contra los propios socios de las cooperativas? ¿Cómo explicar estas prácticas contrarias al buen gobierno de una entidad de consumidores? Quizá la respuesta está en que el proceso de crecimiento va acompañado de la masificación y estandarización de los servicios, lo cual va despersonalizando e "impersonalizando" al "empresario-entidad", con lo que se afectan los fines de la relación cooperativa-socio. $\mathrm{Si}$ a ello se suma algún caso extremo de dirigentes con malas políticas de agencia, alejados del interés de los socios, se termina vulnerando la finalidad del servicio de la cooperativa, pues tendremos al socio en una situación de vulnerabilidad debido al bajo estándar en la entrega de información y algunas prácticas abusivas al mismo.

Lo señalado explica la necesidad de priorizar la protección del consumidor en el tramo en el cual se brinda la información, sin necesidad de distinguir si la prestación proviene de la cooperativa o de cualquier otra empresa en el mercado. Esto desde luego excluye la materia relacionada con la parte asociativa, como lo es la información que se entrega con ocasión de las asambleas generales, el ejercicio de los derechos políticos y económicos de los socios (los vinculados a su calidad de aportantes al patrimonio de la cooperativa, etc.), los procesos electorales internos, etc.

Por lo tanto, desde este otro punto de vista, que compartimos, la tutela del consumidor es una corriente atípica imputable como política por el Estado ante las "fallas" que fundamentalmente se producen con ocasión de la asimetría informativa presente al establecer una relación de consumo, debiendo considerarse dentro del concepto "relación de consumo" no solo a los actos de cambio en el mercado, sino también a 
las prestaciones que nacen directamente del objeto social de la persona jurídica cooperativa, toda vez que lo que se trata de mantener es un estándar mínimo de información para los consumidores ${ }^{3}$.

\section{El acto cooperativo y el derecho de la competencia}

\subsection{La libre y leal competencia dentro de las cooperativas}

La legislación sobre la libre competencia resulta aplicable a las cooperativas en la medida en que estas constituyen una opción empresarial dedicada a satisfacer las necesidades de sus socios frente a las alternativas que puede o no puede ofrecer el mercado. Como señala Ronald Coase (1937) en su obra La naturaleza de la empresa, esta nace cuando el mercado no satisface la necesidad de los agentes económicos.

En ese orden de ideas, cuando no exista una empresa mercantil o su oferta sea muy cara, las necesidades de los consumidores podrán ser satisfechas mediante su afiliación a una cooperativa de usuarios. Por ende, la cooperativa deberá respetar la institucionalidad correspondiente, vale decir, la regulación sobre la libre y leal competencia, pues va a intervenir en el mercado (de factores o de bienes y servicios finales), en el que pueden concurrir otras empresas.

\subsection{Supuestos de afectación a la libre competencia por una cooperativa}

Conforme al Decreto Legislativo 1034 (Decreto Legislativo que aprueba la Ley de Represión de Conductas Anticompetitivas), la libre y leal competencia sanciona las conductas de abuso de posición de dominio y la concertación. A diferencia de otros ordenamientos jurídicos, la concentración de empresas no es controlada y menos considerada infracción.

\subsubsection{El abuso de posición de dominio}

Las cooperativas pueden incurrir en abuso de posición de dominio si de alguna manera restringen indebidamente la competencia y con ello obtienen beneficios y perjudican a otros competidores reales o potenciales.

3 La moderna tendencia del derecho del consumidor lleva a tutelar la prestación de cualquier entidad pública o privada, pues se trata de un derecho funcional, ya que aunque el Estado puede invocar su inclinación por el consumidor como política pública, podría terminar asumiendo un rol contrario a sus fines a través del ejercicio de su actividad empresarial. 
El abuso de posición de dominio podrá consistir en la realización de conductas exclusorias, es decir, aquellas prácticas dirigidas contra los competidores para crear barreras artificiales de acceso al mercado, como los precios predatorios, los boicots, las cláusulas de atadura, los precios y condiciones comerciales discriminatorias, etc., conductas poco usuales en el caso de las cooperativas.

\subsubsection{La concertación}

La jurisprudencia en el Perú ha sido uniforme en cuanto a la necesidad de sancionar la concertación horizontal y un poco contradictoria al sancionar la concertación vertical. Por razones de espacio, nos referiremos únicamente a la primera.

Si las cooperativas que realizan actividades económicas similares en forma independiente se ponen de acuerdo para no competir (repartiéndose mercados $\mathrm{u}$ ofreciendo prestaciones bajo condiciones de comercialización semejantes), obviamente habrán consumado una infracción por concertación ${ }^{4}$. Son ejemplos de esta práctica: los acuerdos de precios, el establecer limitaciones o reparto de cuotas de producción, las limitaciones a las innovaciones tecnológicas o el reparto de áreas geográficas, etc.

Por el contrario, y a modo de ejemplo, si las cooperativas cafetaleras comercializaran el café de sus socios usando un mecanismo de integración (central o federación) que les ofrece el servicio de acopio del grano para tener una oferta exportable adecuada o que les permite generar un valor agregado al producto (como pelado, tostado, envasado y transporte del café), no existirá concertación ${ }^{5}$.

4 Al respecto, el precedente de observancia obligatoria recaído en la Resolución 206-97-TDC (Caso Miguel Segundo Ciccia Vásquez E.I.R.L. vs. Empresa Turística Mariscal Cáceres S.A.) estableció que los acuerdos de fijación de precios y reparto de mercado serán per se ilegales cuando tengan por finalidad restringir la competencia, es decir acuerdos puros o desnudos.

5 Sin embargo, aquellos acuerdos de fijación de precios y reparto de mercado que sean accesorios o complementarios a una integración o asociación convenida y que hayan sido adoptados para lograr una mayor eficiencia de la actividad productiva que se trate, deberán ser analizados caso por caso a fin de determinar la racionalidad o no de estos. Si dependiendo del tipo de actividad productiva a analizarse se determina que la integración acordada entre las empresas es esencial para que dicha actividad se pueda llevar a cabo, entonces dicho acuerdo de integración así como las restricciones de la competencia que se generarían para que dicha actividad sea eficiente estarán permitidos. 
En efecto, aun cuando la central fije un solo precio para todo el café y se fijen las mismas condiciones de comercialización, ello no será reprochable en la medida en que se lleve a cabo dentro del ámbito de la actividad económica de la central. En ese sentido, si la central ha incorporado a su actividad parte del proceso productivo y la comercialización del café, simplemente se trata de una empresa que está ejecutando su propia actividad principal y con eficiencia debe determinar sus costos, precios y, en general, condiciones de comercialización.

La misma regla se aplica a los servicios únicamente accesorios o complementarios de la actividad principal. Por ejemplo: si los cafetaleros mantienen su producción individual y organizan una cooperativa de servicios de transporte cuyos socios son ellos mismos, con el objeto de trasladar el café (justamente de sus socios) hasta el puerto para su exportación, obviamente al ser una empresa de productores los precios serán uniformes, razonables y proporcionales a la cantidad de café transportado.

Vale decir, los servicios principales (directamente relacionados con el cultivo del café) así como los complementarios (transporte, almacenamiento, etc.) pueden existir y organizarse empresarialmente dentro de su propia organización jerárquica, pudiéndose definir en dicho ámbito los precios y las condiciones. No cabe acusar a la cooperativa transportista de ser un cartel oligopólico de potenciales clientes del transporte y querer competir en el nivel de la demanda, pues si las cooperativas se encuentran unidas es porque no hay oferta adecuada para ellas y han tenido que esforzarse para que esta exista.

Otro ejemplo: si varias compañías prestadoras de servicios de transporte interprovincial (a escala nacional) invierten en un terminal terrestre, podrán organizar la operación: su centro de servicios, uniformizar la tarifa, distribuirse las rutas para evitar generar una competencia que las desintegre y poder hacer viable el terminal.

En ese contexto, si cada transportista hiciese lo que quisiera, yendo por cualquier ruta o usando el terminal para ingresar a la ruta que usualmente explota otra compañía, simplemente este carecería de viabilidad y los consumidores perderían una mejora en el servicio: un local central con información sobre rutas y horarios, una cómoda sala de espera, servicios de cafetería y restaurante, embarque y desembarque, seguridad, etc.

En ese sentido, la fijación de precios y el reparto de áreas geográficas podrán darse válidamente, tanto en actividades principales como accesorias o complementarias, en la medida en que sean producto de una 
actividad organizada por dichos agentes, sea que usen una cooperativa, un consorcio o unión temporal de empresas, una sociedad de hecho o una empresa mercantil.

Tampoco cabe que los gremios cooperativos operen como mecanismos de coordinación o recomendación de precios o condiciones de comercialización, pues no es su función. Desde luego, podrán prestar servicios de información general que comprenda representación y defensa institucional, estando facultados incluso a prestar servicios accesorios o complementarios a la actividad principal de la cooperativa $\mathrm{y}$ a determinar sus precios.

\subsubsection{La concentración}

Si las cooperativas se integran por razones de eficiencia en otras cooperativas, centrales, federaciones, consorcios, con el objeto de poder procesar sus productos, compartir una marca, generar una oferta exportable, realizar compras en común para ahorrar costos logísticos, generar una oferta compradora en escala o, en general, desarrollar una actividad económicamente organizada, no estarían generando una conducta infractora.

\subsection{Competencia desleal}

En materia de competencia desleal, la cooperativa es un agente económico más y como tal se encuentra obligada a cumplir con las disposiciones del Decreto Legislativo $1044^{6}$ (Decreto Legislativo que aprueba la Ley de Represión de la Competencia Desleal). En consecuencia, le está prohibido realizar actos de engaño, actividades que generen confusión, denigración, violación de normas, sabotaje empresarial en desmedro de otros competidores (sean cooperativas o empresas mercantiles).

Igualmente, en materia de anuncios publicitarios, las cooperativas deberán cumplir además con los principios de "autenticidad", "legali-

6 Sobre el particular, deberá cumplir de manera irrestricta con lo dispuesto en la cláusula general:

Artículo 6.- Cláusula general.-

6.1.- Están prohibidos y serán sancionados los actos de competencia desleal, cualquiera sea la forma que adopten y cualquiera sea el medio que permita su realización, incluida la actividad publicitaria, sin importar el sector de la actividad económica en la que se manifiesten.

6.2.- Un acto de competencia desleal es aquél que resulte objetivamente contrario a las exigencias de la buena fe empresarial que deben orientar la concurrencia en una economía social de mercado. 
dad" y "adecuación social"7, por lo que no podrán difundir publicidad que infrinja dichos principios jurídicos.

Veamos un ejemplo sobre el "principio de legalidad". Supongamos que una cooperativa de ahorro y crédito omite publicar en su página web (en la que publicita sus servicios) que sus operaciones se realizan sin captar recursos del público y que los depósitos de sus asociados no se encuentran cubiertos por el "Fondo de Seguro de Depósitos", como lo dispone el artículo 8 del "Reglamento de las Cooperativas de Ahorro y Crédito no autorizadas a operar con recursos del público" 8 . En ese caso habrá incurrido en una evidente infracción al principio de legalidad al haber difundido la operatividad de sus servicios sin respetar las normas imperativas que se aplican a la actividad publicitaria.

7 Artículo 16.- Actos contra el principio de autenticidad.-

16.1.-Consisten en la realización de actos que tengan como efecto, real o potencial, impedir que el destinatario de la publicidad la reconozca claramente como tal.

16.2.-Constituye una inobservancia a este principio difundir publicidad encubierta bajo la apariencia de noticias, opiniones periodísticas o material recreativo, sin advertir de manera clara su naturaleza publicitaria. Es decir, sin consignar expresa y destacadamente que se trata de un publirreportaje o un anuncio contratado.

Artículo 17.- Actos contra el principio de legalidad.-

17.1.-Consisten en la difusión de publicidad que no respete las normas imperativas del ordenamiento jurídico que se aplican a la actividad publicitaria.

17.2.-Constituye una inobservancia de este principio el incumplimiento de cualquier disposición sectorial que regule la realización de la actividad publicitaria respecto de su contenido, difusión o alcance.

$[\ldots]$

Artículo 18.- Actos contra el principio de adecuación social.-

Consisten en la difusión de publicidad que tenga por efecto:

a) Inducir a los destinatarios del mensaje publicitario a cometer un acto ilegal o un acto de discriminación u ofensa por motivo de origen, raza, sexo, idioma, religión, opinión, condición económica o de cualquier otra índole; b) Promocionar servicios de contenido erótico a un público distinto al adulto. La difusión de este tipo de publicidad solamente está permitida en prensa escrita de circulación restringida para adultos y, en el caso de radio y/o televisión, dentro del horario de una (1:00) a cinco (5:00) horas.

8 Artículo 8.- Transparencia

En la publicidad que efectúen las Cooperativas sobre sus operaciones y servicios, deberán indicar claramente que no captan recursos del público y que los depósitos de los asociados no se encuentran cubiertos por el Fondo de Seguro de Depósitos. [...]. 


\section{A modo de conclusión}

En virtud de lo expuesto, pueden señalarse a modo de conclusión los siguientes puntos:

- El acto cooperativo es aquel acto interno que se lleva a cabo entre la cooperativa y sus socios dentro de los alcances de su objeto social, sin mediar un fin lucrativo.

- El acto cooperativo puede ser comprendido como "acto de consumo" sujeto a la tutela del derecho del consumidor bajo una dimensión más extensiva y omnicomprensiva, toda vez que dentro de las cooperativas de usuarios se permite la prestación de servicios a los socios sujeta a una contraprestación económica, pues lo que en buena cuenta busca establecer el derecho del consumidor es un estándar mínimo de tutela en materia de asimetría informativa.

- Debería precisarse mediante ley la noción de la relación de consumo, ampliando sus alcances al acto cooperativo.

- La aplicación de dicha normativa se justifica en el hecho de que es evidente que una cooperativa está actuando contra los intereses de sus socios, que despersonaliza por la masificación y crea falla en los estándares del deber de información. Además que al no existir oposición de intereses entre proveedor-consumidor, dicho desvío resulta anómalo.

- Habrá concertación y se vulnerará la regulación sobre la libre competencia en la medida en que los socios de una cooperativa (por ejemplo, pequeños empresarios) no se sirvan de ella para darle valor agregado a sus productos o complementen su proceso productivo para alcanzar una actividad accesoria o complementaria que les brinde eficiencia a su actividad económica, sino que, por el contrario, la usen solo como "fachada" para coordinar precios, condiciones de comercialización, reparto de mercados, etc.

- La agrupación de los socios en cooperativas, asociaciones en participación, sociedades de hecho, uniones transitorias de empresas o consorcios no configurará una concertación o acuerdo prohibido siempre y cuando a través de ese medio las decisiones de fijación de precios o condiciones de comercialización se lleven a cabo en el contexto del desarrollo de una actividad económica que mejore su eficiencia. 
- Las cooperativas en general deberán cumplir con la regulación sobre libre competencia y competencia desleal como cualquier agente económico, teniendo en cuenta las normas especiales y sectoriales que les son aplicables.

\section{Referencias}

Botana García, G., \& Ruiz Muñoz, M. (1999). Curso sobre protección jurídica de los consumidores. Madrid: McGraw-Hill.

Bullard Gonzales, A. (2003). Derecho y economía. Lima: Palestra.

Coase, R. H. (1937). La naturaleza de la empresa. UK: Económico.

Cracogna, D. (6-10 de octubre de 2013). El acto cooperativo y la defensa del consumidor. Ponencia presentada en el Congreso Continental de Derecho Cooperativo, llevado a cabo en el marco de la XVIII Conferencia Regional ACI Américas, en Guarujà. Sã o Paulo, Brasil.

Fridman, N., \& Pérez Constanzó, G. (2005). Derechos del consumidor y seguridad en los productos. En Foro y Regulación del Derecho de la Competencia. Buenos Aires. Disponible en http://www.econ.uba. ar/planfenix/docnews/Regulacion $\% 20 \mathrm{y} \% 20$ defensa $\% 20 \mathrm{de} \% 20$ la\%20competencia/Perez\%20Constanzo.pdf

Morales Acosta, A. (2008). Temas de protección al consumidor y buenas prácticas de mercado. Lima: Asesorandina.

Uribe Garzón, C. (2002). Bases del cooperativismo. (5. ${ }^{\mathrm{a}}$ ed.). Bogotá: Guadalupe Ltda. 